\title{
Temperature, ozone, and mortality in urban and non-urban counties in the northeastern United States
}

\author{
Jaime Madrigano ${ }^{1 *}$, Darby Jack², G Brooke Anderson ${ }^{3}$, Michelle L Bell ${ }^{4}$ and Patrick L Kinney ${ }^{2}$
}

\begin{abstract}
Background: Most health effects studies of ozone and temperature have been performed in urban areas, due to the available monitoring data. We used observed and interpolated data to examine temperature, ozone, and mortality in 91 urban and non-urban counties.

Methods: Ozone measurements were extracted from the Environmental Protection Agency's Air Quality System. Meteorological data were supplied by the National Center for Atmospheric Research. Observed data were spatially interpolated to county centroids. Daily internal-cause mortality counts were obtained from the National Center for Health Statistics (1988-1999). A two-stage Bayesian hierarchical model was used to estimate each county's increase in mortality risk from temperature and ozone. We examined county-level associations according to population density and compared urban $\left(\geq 1,000\right.$ persons/mile $\left.{ }^{2}\right)$ to non-urban $\left(<1,000\right.$ persons/mile $\left.{ }^{2}\right)$ counties. Finally, we examined county-level characteristics that could explain variation in associations by county.
\end{abstract}

Results: A 10 ppb increase in ozone was associated with a $0.45 \%$ increase in mortality (95\% Pl: $0.08,0.83)$ in urban counties, while this same increase in ozone was associated with a $0.73 \%$ increase ( $95 \% \mathrm{PI}: 0.19,1.26)$ in non-urban counties. An increase in temperature from $70^{\circ} \mathrm{F}$ to $90^{\circ} \mathrm{F}\left(21.2^{\circ} \mathrm{C} 32.2^{\circ} \mathrm{C}\right)$ was associated with a $8.88 \%$ increase in mortality $(95 \% \mathrm{Pl}: 7.38,10.41)$ in urban counties and a $8.08 \%$ increase $(95 \% \mathrm{Pl}: 6.16,10.05)$ in nonurban counties. County characteristics, such as population density, percentage of families living in poverty, and percentage of elderly residents, partially explained the variation in county-level associations.

Conclusions: While most prior studies of ozone and temperature have been performed in urban areas, the impacts in non-urban areas are significant, and, for ozone, potentially greater. The health risks of increasing temperature and air pollution brought on by climate change are not limited to urban areas.

Keywords: Climate change, Epidemiology, Mortality, Ozone, Time-series models

\section{Introduction}

Ground level ozone and temperature are current environmental health stressors that are expected to worsen with climate change. Daily mortality is associated with short-term peaks in both ozone and temperature [1-6], which often co-occur during warm months. However, one recent study found that the association between ozone and mortality depends on the specification of temperature in the model [7]. Since the formation of

\footnotetext{
* Correspondence: jaime.madrigano@rutgers.edu

'Department of Environmental and Occupational Health, School of Public Health, Rutgers, The State University of New Jersey, Piscataway, NJ, USA

Full list of author information is available at the end of the article
}

ozone is temperature dependent, ozone may or may not be included in models that assess temperature-related mortality, depending on the research question [8].

Additionally, environmental data are often rich in time but sparse in space hampering health effects analysis and leading to generalizations from studies where data are available. Most health effects studies of ozone and temperature have been performed in urban areas [1,9-11] and very limited work has been done in suburban and rural areas [12-14] with conflicting results as to whether the magnitude of risk is the same in urban and non-urban areas. The disparity in number of research studies for urban and non-urban areas relates to the nature of large- 
scale monitoring networks for ozone monitors, which are more likely to be in urban areas, and concerns of population size, which are less problematic for studies focusing on urban populations. Similarly, many public health preparedness efforts for climate change adaptation (e.g. heathealth warning systems) have been concentrated in major metropolitan areas [15] and there is some evidence that rural communities are not well represented in climate and health research [16]. Although, several recent studies have suggested that heat-health risks are also of concern in rural areas [17-19]. If non-urban areas are also at risk, local public health departments may be ill equipped to deal with the health impacts of a changing climate, or even to develop efficient policies to mitigate the current risks. Research results from one area may not be applicable to another due to differences in population demographics, health care systems, baseline health care status, and other factors [20-22].

In this study, we used a combination of observed and interpolated data to examine the relationship between temperature, ozone, and mortality in 91 counties in the Northeastern United States, comprising urban, suburban, and rural areas. We wanted to determine how the use of interpolated data influenced our results, compared to those using observed data alone. We also wanted to evaluate whether the risk was the same in urban versus non-urban counties in our study area, given the paucity of information on health risks of air pollution in non-urban regions and since assessing these differences within a given geographical region remains an understudied area of research. We hypothesized that the risks in non-urban areas would be at least as great as those in urban areas. Finally, we assessed whether county characteristics could explain variation in the county-level associations.

\section{Methods}

We obtained daily mortality records from the National Center for Health Statistics for every county in the states of New York, New Jersey, and Connecticut. There are 62 counties in New York, 21 counties in New Jersey, and 8 counties in Connecticut, for a total of 91 counties. Data were obtained for the years 1988 through 1999. Daily mortality counts were computed by adding all deaths from internal causes (i.e., non-accidental deaths) that occurred on each day in each county. We performed this analysis in two phases; first, using only observed (i.e., measured) ozone and temperature data, and second, incorporating interpolated data.

\section{Exposure}

Ozone measurements were extracted from EPA's AQS (Air Quality System) for all stations in the eastern U.S. from 1988 - 1999. For ozone, the daily maximum 8-hour average was derived from hourly ozone data obtained from AQS and matched to a master station file obtained from EPA. A daily mean 8-hour ozone value from all ozone-monitoring stations in each county was calculated. We restricted attention to 12 counties ( 2 in Connecticut, 2 in New Jersey, and 8 in New York) for which both ozone and temperature data were available for at least $75 \%$ of possible days. Ten counties met these criteria for the entire study period (1988 - 1999). For two counties (Chautauqua, NY and New Haven, CT), the study period was restricted to years that met the criteria, 1992 - 1999 and 1993 1999, respectively. We obtained meteorological data (daily maximum temperature) from the CISL Research Data Archive (http://rda.ucar.edu/datasets/ds472.0/).

In the second phase of this analysis, observed ozone and temperature data from all sites within a rectangular domain that encompassed the tri-state area were spatially interpolated (kriging) to the 91 population-weighted county centroids (this is illustrated by Additional file 1: Figures S1 and S2). We first estimated variograms for each day for each variable. Maximum likelihood fitting was then used to fit five alternative theoretical variogram models (circular, spherical, cubic, Gaussian, and exponential) to the empirical variogram. The best fit was determined for each day and variable by cross-validation and maximum likelihood goodness of fit metrics. Using this approach, data were interpolated to population-weighted county centroids. Population-weighted centroids were computed as the point in each county that minimized the sum of squared distances to the people living there. This method generates a centroid that represents the average center of persons' residences in the county, as opposed to areaweighting, which notes the center of the area. Thus, this method accounts for differences in population density throughout the county.

\section{Statistical analysis}

We performed this analysis in two phases. In the first phase, we used data only from counties $(n=12)$ with observed environmental data for at least $75 \%$ of available days in a given year for at least 5 years. In the second phase, we incorporated interpolated exposure data for all 91 counties for all possible days. During each phase, we applied a two-stage Bayesian hierarchical model. In the first stage, we estimated increase in mortality risk using generalized linear models with an over-dispersed Poisson distribution for each county. We ran separate models to estimate the effects of daily 8-hour maximum ozone and daily maximum temperature. When assessing the effect of temperature, we ran models without control for ozone and included ozone as a covariate as a sensitivity analysis. When assessing the effect of ozone, our primary analysis included temperature as a covariate. In all models, we controlled for day of the week and time trends, to account for seasonal and long-term 
time trends. The general structure of each county-specific model was:

$$
\begin{aligned}
\log \left(\mu^{c}{ }_{t}\right)= & \beta_{0}{ }^{c}+\beta^{c} \mathrm{OZONE}_{t}{ }^{c}+\mathrm{ns}\left(\mathrm{T}^{c}{ }_{t}, 3\right) \\
& +y^{c} \mathrm{DOW}_{t}+\mathrm{ns}\left(\text { time }_{t}, d f\right)
\end{aligned}
$$

where

$$
\begin{aligned}
& \mu^{c}{ }_{t}=\text { the expected mortality rate for county } c \text { on day } t \\
& \beta_{0}{ }^{c}=\text { the model intercept } \\
& \begin{aligned}
\beta^{c}=\text { the regression coefficient for mortality for a } \\
\text { unit increase in ozone for county c }
\end{aligned} \\
& \begin{aligned}
& \mathrm{OZONE}_{t}{ }^{c}= \text { the average of the daily maximum } \\
& \text { 8-hour average ozone for day } \mathrm{t} \\
& \text { and day } \mathrm{t}-1
\end{aligned}
\end{aligned}
$$

$n s\left(T_{t}^{c}\right)=$ the natural cubic spline of the average of maximum temperature for county $c$ on day $t$ and day $\mathrm{t}-1$, with three degrees of freedom

$y^{c}=$ the regression coefficient for day of the week for county $c$

DOW $t=$ the categorical variable for day of the week

$\mathrm{ns}\left(\right.$ time $\left._{\mathrm{t}}\right)=$ the natural cubic spline of a variable representing time to adjust for long-term trends with 4 degrees of freedom per year.

We estimated a separate effect for each county using equation 1 and then generated an overall effect estimate across all counties by combining the county-specific effects, accounting for the estimate's statistical uncertainty, using a Bayesian hierarchical model through the TwoLevel Normal independent sampling estimation (TLNise) package in R [23]. Similar community-specific models and Bayesian hierarchical modeling strategies were used in previous work to analyze how ozone and temperature are associated with mortality risk [20,24]. We calculated the relative increase in mortality for a $10 \mathrm{ppb}$ increase in daily 8-hour maximum ozone. To quantify results from the non-linear function relating temperature to risk of mortality, we estimated a heat effect by comparing the increase in mortality at $90^{\circ} \mathrm{F}$, corresponding to approximately the $99^{\text {th }}$ percentile of the temperature distribution of all counties, versus $70^{\circ} \mathrm{F}\left(32.2^{\circ} \mathrm{C}\right.$ versus $\left.21.1^{\circ} \mathrm{C}\right)$

Due to data availability during the study period at the county level, we were unable to account for other environmental pollutants (e.g., particulate matter) that may be correlated with ozone and associated with daily mortality. However, in one county (New Haven, CT) where consistent $\mathrm{PM}_{10}$ data were available throughout the study period, we performed a sensitivity analysis to determine if adjustment for $\mathrm{PM}_{10}$ affected the association between ozone and mortality.

We next compared the estimates between urban and non-urban counties. We stratified our data by population density, defining urban counties as those having a population density greater than or equal to 1,000 persons per square mile and non-urban counties as those having a population density of less than 1,000 persons per square mile (one dimension used by the U.S. Bureau of the Census to define urban). Population density estimates were obtained from the year 2000 US Census, and a sensitivity analysis used data from the 1990 Census. We then computed two summary estimates; one for the urban counties $(n=23)$ and one for the non-urban counties $(\mathrm{n}=68)$.

Finally, to determine if heterogeneity between counties could be explained by population characteristics, we fit the following Bayesian hierarchical regression model:

$$
\begin{aligned}
& \hat{\beta}^{c} \mid \beta^{c}, \hat{v}^{c \sim} N\left(\beta^{c}, \hat{v}^{c}\right) \\
& \beta^{c} \mid \alpha_{0}, \alpha_{1 j}, \tau^{2 \sim} N\left(\alpha_{0}+\sum_{j} \alpha_{1 j}\left(x_{j}^{c}-\bar{x}_{j}\right), \tau^{2}\right)
\end{aligned}
$$

where

$$
\begin{aligned}
\hat{\beta}^{c}, \beta^{c}= & \text { estimated and true log relative risk effect } \\
& \text { estimate, respectively, for ozone or } \\
& \text { temperature on mortality for county c }
\end{aligned}
$$

$\hat{v}^{c}=$ estimated statistical variance of $\hat{\beta}^{c}$

$x_{j}^{c}=$ value of characteristic variable $\mathrm{j}$ for county $\mathrm{c}$

$\bar{x}_{j}=$ average value of characteristic variable $\mathrm{j}$ across all counties

$\alpha_{0}=$ average log relative risk for an "average county"

$\alpha_{1 j}=$ change in the relative risk, $\beta^{c}$, for a unit increase in $x_{j}^{c}-\bar{x}_{j}$
$\tau^{2}=$ variance across counties of the true county-specific relative risks, $\beta^{c}$, unexplained by the community-specific characteristics $\left(x_{j}^{c}\right.$ for all $\left.\mathbf{j}\right)$

The following county characteristics were obtained from the United States Census summary files: proportion of county families living in poverty, population density, and proportion of residents over the age of 65 . We also investigated whether mean county ozone concentration or temperature modified the county-specific results. All of our analyses were restricted to warm months (April October) as this time of the year has the highest levels 
of our exposures of interest (ozone and temperature). Analyses were conducted using R 2.8.1 (R Foundation for Statistical Computing, Vienna, Austria).

\section{Results}

Summary statistics for mortality, ozone, and temperature for each of the 12 counties used in the analysis with observed data, as well as summaries for these 12 counties, all 91-study counties, 23 urban counties, and 68 non-urban counties, are shown in Table 1 . Across all 91 counties, the mean observed daily 8-hour maximum ozone concentration was $46 \mathrm{ppb}$ and the mean warm-month daily maximum temperature was $74^{\circ} \mathrm{F}$. On average, there were 6 deaths per day (range 0 to 99 ) across the 91 counties.

\section{Observed data analysis}

In the analysis of 12 counties with observed data, we found that an increase in exposure to ozone was associated with an increase in risk of mortality in the majority of counties (Figure 1a). When we generated an overall effect across counties by combining county-specific effect estimates, we found that a $10 \mathrm{ppb}$ increase in daily 8-hour maximum ozone was associated with a $0.80 \%$ increase in mortality [95\% Posterior Interval (PI): 0.31, 1.30], after adjusting for temperature. Similarly, we found that mortality was statistically significantly increased in all but one county when comparing days of $90^{\circ} \mathrm{F}$ versus $70^{\circ} \mathrm{F}$ (Figure $1 \mathrm{~b}$ ). Across counties, we found that there was an increase in mortality of $10.11 \%$ (95\% PI:
$8.34,11.91)$ when comparing expected mortality at $90^{\circ} \mathrm{F}$ versus $70^{\circ} \mathrm{F}$.

\section{Kriging data analysis}

In our analysis of 91 counties using data from kriging methods, we found some variability in the effect estimates for ozone and temperature (Figure $2 \mathrm{a}$ and b), but overall, across counties, we found a $10 \mathrm{ppb}$ increase in daily 8hour maximum ozone was associated with a $0.55 \%$ increase in mortality (95\% PI: 0.25, 0.86), after adjustment for temperature. There was an increase in mortality of 8.44\% (95\% PI: 7.24, 9.65) when comparing expected mortality at $90^{\circ} \mathrm{F}$ versus $70^{\circ} \mathrm{F}$.

\section{Sensitivity analysis}

In our models for the observed data we used a spline with 7 degrees of freedom per year to control for time trends, however, due to model convergence problems when using data for all 91 counties, we reduced the degrees of freedom to 4 per year for the 91-county analysis. To assess how this would impact our results, we re-ran the models for only the 12 counties with observed data, but using 4 degrees of freedom per year. A comparison of the results across all counties from these three methods is shown in Table 2. We found that using 4 degrees of freedom instead of 7 degrees of freedom did not substantially impact the results.

Although we did not have complete data for particulate matter for all counties during our study period, we ran a sensitivity analysis for New Haven county (CT),

Table 1 Environmental and mortality data for study area, April - October, 1988 - 1999

\begin{tabular}{|c|c|c|c|c|c|c|c|c|c|}
\hline & \multicolumn{3}{|c|}{ Ozone (ppb) } & \multicolumn{3}{|c|}{ Maximum Temperature $\left({ }^{\circ} \mathrm{F}\right)$} & \multicolumn{3}{|c|}{ Mortality (n/day) } \\
\hline & Minimum & Maximum & Mean & Minimum & Maximum & Mean & Minimum & Maximum & Mean \\
\hline Hartford, СТ & 0 & 146 & 44.3 & 33.5 & 100.5 & 73.4 & 5 & 34 & 17.4 \\
\hline New Haven, CT & 4 & 127 & 44.6 & 32 & 97 & 71.1 & 7 & 36 & 17.2 \\
\hline Atlantic, NJ & 3 & 136 & 53.8 & 41 & 100 & 74.4 & 0 & 15 & 5.2 \\
\hline Essex, NJ & 1 & 145 & 37.1 & 40 & 105 & 75.8 & 4 & 40 & 17.6 \\
\hline Albany, NY & 0 & 116 & 42.8 & 30 & 98 & 71.2 & 0 & 18 & 6.1 \\
\hline Chautauqua, NY & 10 & 107 & 49.9 & 24 & 93 & 66.3 & 0 & 11 & 3.2 \\
\hline Chemung, NY & 4 & 118 & 45.3 & 34 & 102 & 71.8 & 0 & 9 & 2.2 \\
\hline Erie, NY & 1 & 134 & 44.8 & 31 & 96 & 60.1 & 10 & 45 & 24.4 \\
\hline New York, NY & 3.5 & 149 & 45.4 & 39 & 102 & 74.8 & 11 & 67 & 34.3 \\
\hline Niagara, NY & 6 & 134 & 46.5 & 30 & 99 & 70.1 & 0 & 15 & 4.8 \\
\hline Suffolk, NY & 8 & 138 & 47.7 & 37 & 101 & 71.8 & 11 & 47 & 23.9 \\
\hline Westchester, NY & 3 & 150 & 45.2 & 34 & 100 & 72.5 & 3 & 33 & 17.0 \\
\hline 12 Counties (using observed data) & 1 & 149 & 45.6 & 29 & 104 & 71.8 & 0 & 67 & 14.4 \\
\hline 91 Counties (using kriging data) & 4.7 & 136.6 & 45.7 & 35.2 & 102.4 & 73.8 & 0 & 99 & 6.2 \\
\hline 23 Urban Counties & 4.7 & 133.5 & 45.6 & 40.7 & 102.4 & 75.8 & 0 & 99 & 17.2 \\
\hline 68 Non-Urban Counties & 5.3 & 136.6 & 45.7 & 35.2 & 100.0 & 73.1 & 0 & 45 & 2.5 \\
\hline
\end{tabular}



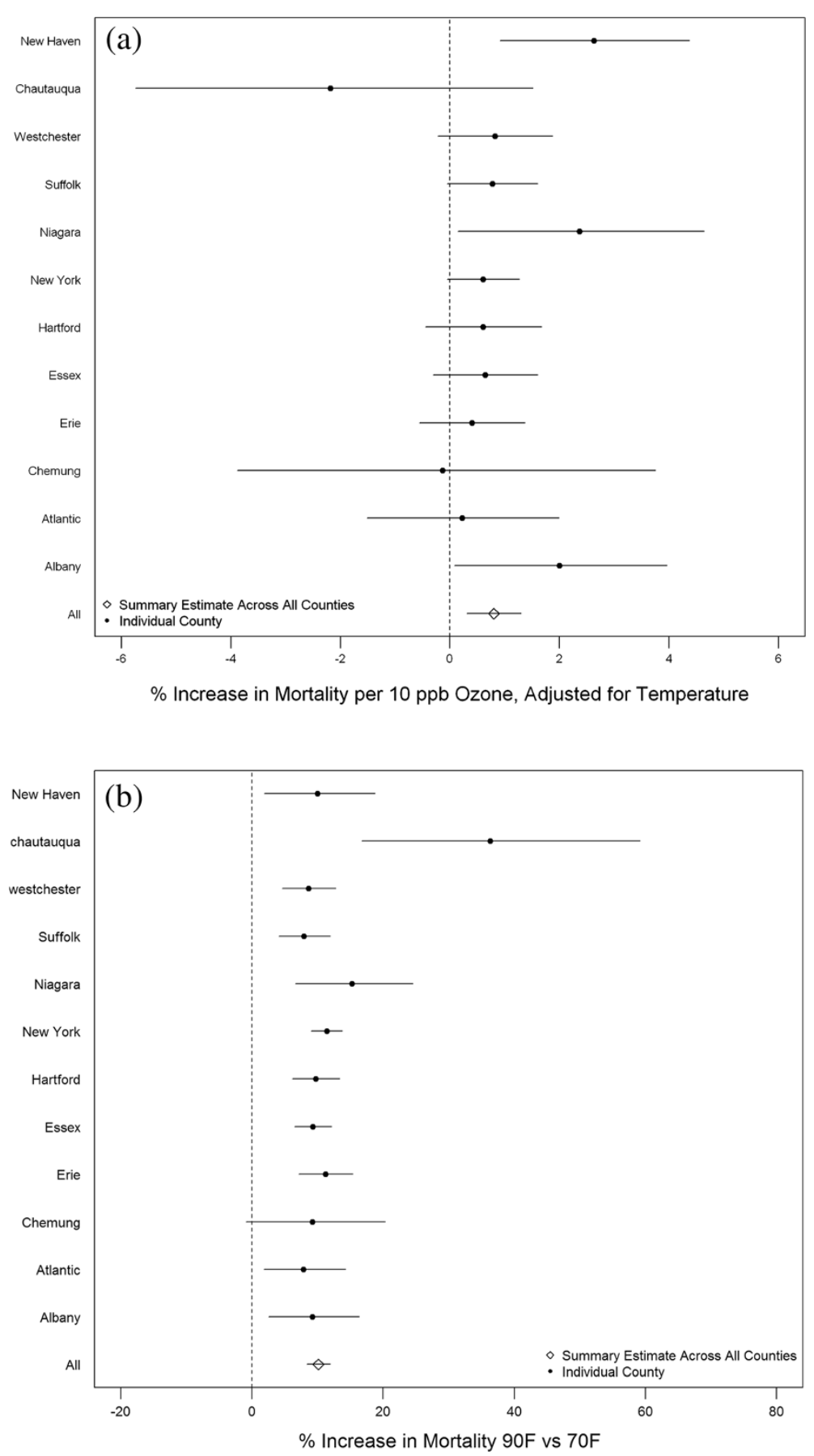

Figure 1 Point estimates and 95\% posterior intervals showing association between (a) ozone and mortality in twelve counties and (b) temperature and mortality in twelve counties.

where sufficient $\mathrm{PM}_{10}$ data were available. Without adjustment for $\mathrm{PM}_{10}$, there was a $2.54 \%$ (95\% PI: 0.78 , 4.33) increase in mortality for a $10 \mathrm{ppb}$ increase in daily 8-hour maximum ozone in New Haven. After adjustment for $\mathrm{PM}_{10}$, there was a $2.49 \%$ (95\% PI: 0.69, 4.31) increase in mortality for a $10 \mathrm{ppb}$ increase in daily 8-hour maximum ozone in New Haven.

\section{Urban and non-urban analysis}

When we stratified our data into urban and non-urban counties, the effect of ozone, after adjusting for temperature, in urban counties was a $0.45 \%$ (95\% PI: $0.08,0.83$ ) increase in mortality for a $10 \mathrm{ppb}$ increase in daily 8-hour maximum ozone. Across non-urban counties, there was a $0.73 \%$ (95\% PI: $0.19,1.26)$ increase in mortality for a $10 \mathrm{ppb}$ 

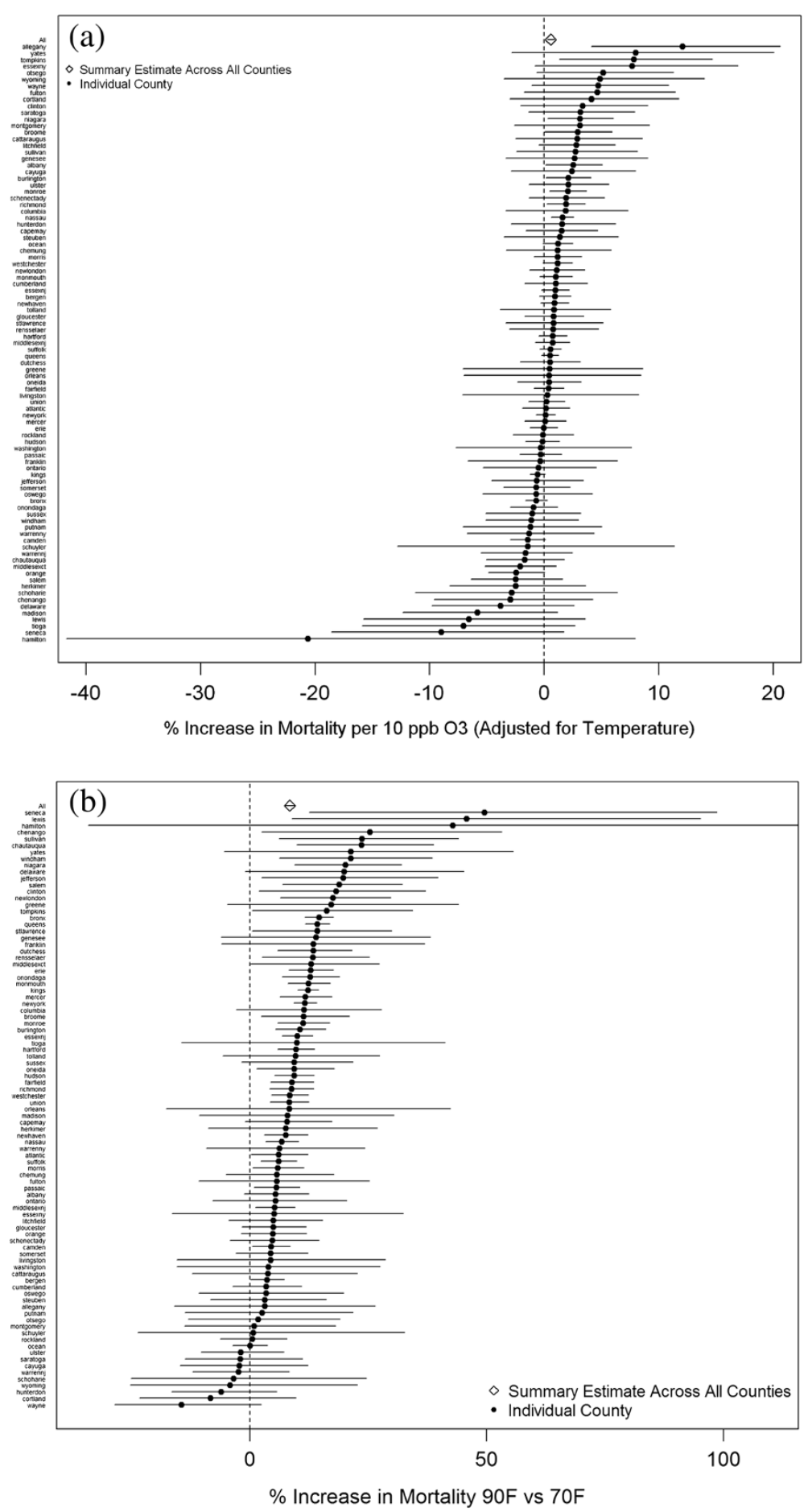

Figure 2 Point estimates and 95\% posterior intervals showing association between (a) ozone and mortality in 91 counties and (b) temperature and mortality in 91 counties.

increase in daily 8-hour maximum ozone. When assessing the impact of temperature across urban counties, there was an $8.88 \%$ (95\% PI: $7.38,10.41)$ increase in mortality comparing expected mortality at $90^{\circ} \mathrm{F}$ to $70^{\circ} \mathrm{F}$. Across nonurban counties, this estimate was 8.08\% (95\% PI: 6.16,
10.05). Figure $3 \mathrm{a}$ and $\mathrm{b}$ show the variation in these estimates by county and according to urban or non-urban classification. A sensitivity analysis using population density estimates from the 1990 US Census did not impact these results. 
Table 2 Summary estimates across counties

\begin{tabular}{|c|c|c|c|c|c|c|c|c|}
\hline \multirow[b]{3}{*}{ Data } & \multicolumn{4}{|c|}{ Increase in Mortality for a $10 \mathrm{ppb}$ Increase in Ozone } & \multicolumn{4}{|c|}{ Increase in Mortality Comparing $90^{\circ} \mathrm{F}$ to $70^{\circ} \mathrm{F}$} \\
\hline & \multicolumn{2}{|c|}{ Unadjusted } & \multicolumn{2}{|c|}{ Adjusted for temperature } & \multicolumn{2}{|c|}{ Unadjusted } & \multicolumn{2}{|c|}{ Adjusted for ozone } \\
\hline & $\%$ Increase & PI & $\%$ Increase & PI & $\%$ Increase & PI & $\%$ Increase & PI \\
\hline 12 counties, $7 \mathrm{df}$ & 1.54 & $(1.19,1.90)$ & 0.80 & $(0.31,1.30)$ & 10.11 & $(8.34,11.91)$ & 6.67 & $(4.13,9.27)$ \\
\hline 12 counties, $4 \mathrm{df}$ & 1.50 & $(1.14,1.86)$ & 0.70 & $(0.10,1.22)$ & 9.63 & $(7.42,11.89)$ & 6.39 & $(2.93,9.97)$ \\
\hline 91 counties, 4 df & 1.39 & $(1.22,1.57)$ & 0.55 & $(0.25,0.86)$ & 8.44 & $(7.24,9.65)$ & 5.87 & $(3.95,7.82)$ \\
\hline
\end{tabular}

ppb parts per billion

$\mathrm{Pl}$ posterior interval.

$\mathrm{df}$ degrees of freedom per year for spline of time in model.

\section{County characteristic effect modification}

Urban counties had a higher mean population density, proportion of families living in poverty, mean temperature, and lower proportion of residents over the age of 65 (Table 3). Table 4 shows the results of the effect modification analysis, including the overall relative increase in mortality after adjusting for the county characteristic and the percentage change in the mortality effect estimate due to each county characteristic. The percent of families living in poverty and population density both modified the association of temperature and ozone with mortality. With increasing levels of these characteristics, there was a greater association between temperature and mortality and a lower association between ozone and mortality. The percentage of residents over 65 in a county only explained heterogeneity of the ozone estimate, which increased with a greater number of residents over 65 . Variation in mean temperature and ozone in a county did not explain any of the heterogeneity observed in our results.

\section{Discussion}

In this analysis of 91 counties in the Northeastern United States, we found that ozone and temperature were independently associated with daily mortality. Several studies have shown an association between ozone and all-cause mortality [1,2,25] and our estimate of the association between ozone on mortality is consistent with that seen in a study of 95 urban communities in the US [1]. Similarly, our finding of an association between heat and all-cause mortality is consistent with the literature [26].

Recently, there has been a discussion in the literature of the most appropriate way to adjust for temperature when examining ozone-related mortality, as well as the appropriateness of controlling for ozone in studies of temperature-related mortality. Pattenden and colleagues found that their estimate of ozone-related mortality was most sensitive to adjustment by temperature when maximum daily temperature was used [7], and therefore, we present results for ozone adjusted for maximum daily temperature. In assessing temperature-related mortality, some studies adjust for ozone and others do not. As Reid and colleagues outline, ozone can cause mortality, but it is unlikely to have a sufficient impact on local temperature to cause a health response [8]. Therefore, ozone can be thought of as a causal intermediate in the relationship between temperature and mortality, but is unlikely to confound the association between temperature and mortality. We primarily present the results of models examining temperature-related mortality, unadjusted for ozone, but also show these results adjusted for ozone. The former can be thought of as the total effect of temperature on mortality, including through any increases in ozone concentration it causes, while the latter can be thought of as the controlled direct effect of temperature on mortality.

In this study we used a combination of measured and interpolated data to assess exposure across three states in the Northeast. Although more extensive methods of estimating air pollution levels are available, we found that a method of interpolation provided useful information, and future studies may investigate other approaches to estimate ozone levels. By incorporating additional estimates of ozone into our analysis, we were able to evaluate the health impacts of ozone and temperature in every county across the tri-state region, including those without monitors. Additionally, we were able to generate an overall effect estimate using more information throughout the region (91 as opposed to 12 counties), as well as examine differences in urban and non-urban counties. Finally, by using this expanded set of counties, and matching it to publicly available data, we were able to examine a set of population characteristics as explanatory variables for the observed variation in results.

Previous large studies in the US, have estimated that a $10 \mathrm{ppb}$ increase in ozone contributes to an increased risk of mortality of between $0.39 \%$ ( $95 \%$ CI: $0.26,0.51$ ) [2] and $0.52 \%$ (95\% PI: $0.27,0.77)$ [1], which is consistent with our overall result of a $0.55 \%(95 \%$ PI: $0.25,0.86)$ increase. However, when we stratified counties by a measure of urbanicity (above or below 1,000 persons $/ \mathrm{mile}^{2}$ ), we found that the point estimate for the association between ozone and mortality was higher for non-urban counties. Although the confidence intervals between the two estimates overlapped, the central estimate for nonurban counties was 1.6 times greater than the estimate for urban counties. Since most prior investigations of ozone and mortality have been conducted in urban 


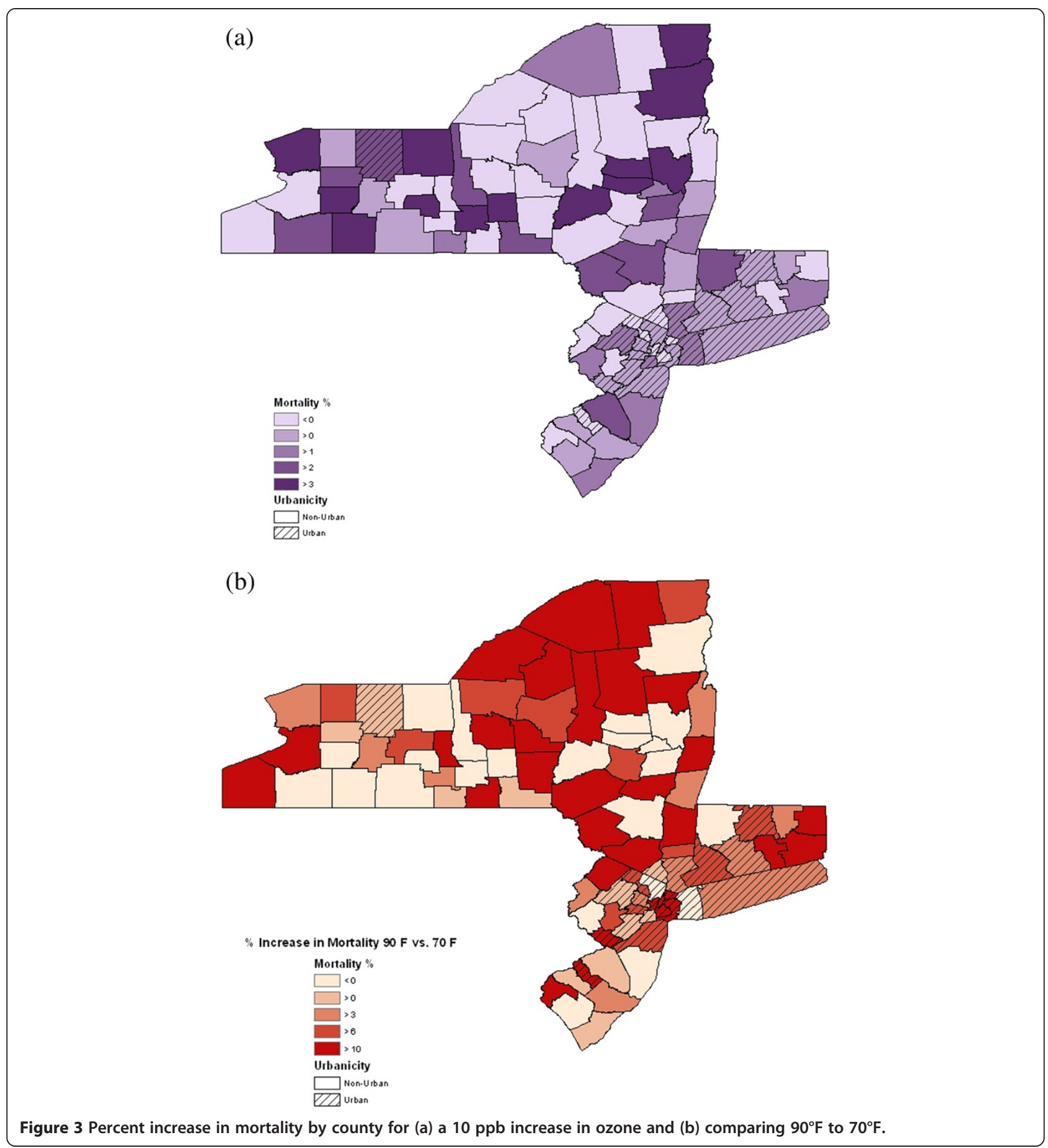

areas, this may indicate that the public health burden of ozone is even greater than previously estimated. Our assessment of the impact of temperature found that significant associations between temperature and mortality persisted in both urban and non-urban counties. This indicates that the health impacts of temperature are not limited to the "urban heat island". Few other studies in the U.S. have examined temperature-related mortality and morbidity across urban, suburban, and rural areas, but there are some indications that being an urban resident does not necessarily make one more vulnerable to heat $[14,19]$.

Studies indicate that many local governments do not feel adequately prepared to address the health impacts of heat [27] and, specifically, in a survey of local health departments in New York state, the majority of respondents 
Table 3 County characteristics by urban and non-urban classification

\begin{tabular}{lcc}
\hline & $\begin{array}{c}\text { Urban counties } \\
(\mathbf{n}=\mathbf{2 3}) \\
\text { Mean } \pm \text { SD }\end{array}$ & $\begin{array}{c}\text { Non-Urban counties } \\
(\mathbf{n}=\mathbf{6 8}) \\
\text { Mean } \pm \text { SD }\end{array}$ \\
\hline \% Families in poverty & $8.9 \pm 6.3$ & $7.2 \pm 2.6$ \\
Population density, & $9,390.4 \pm 15,756.8$ & $231.3 \pm 224.8$ \\
person/mile & & \\
\% Over 65 & $12.7 \pm 1.3$ & $14.0 \pm 2.6$ \\
Ozone, ppb & $45.6 \pm 2.5$ & $45.7 \pm 2.8$ \\
Temperature, ${ }^{\circ}{ }^{2}$ & $75.8 \pm 1.4$ & $73.1 \pm 2.0$ \\
\hline
\end{tabular}

did not feel that their department had the necessary expertise to assess potential public health risks of climate change in their jurisdiction [28]. New York, New Jersey, and Connecticut include both urban and non-urban areas and the decentralized public health structure, along with limited budgets, can mean that public health preparedness for climate change can be a challenge. Our findings indicate that both urban and non-urban areas should be prepared to address this challenge.

When we examined county characteristics that might explain the observed variation in our effect estimates, we found that greater poverty in a county was associated with larger effect estimates for heat and mortality. This is consistent with other studies that have examined modification in the temperature-mortality association. Both individual and neighborhood characteristics related to lower socioeconomic position have been found to enhance the relationship between temperature and mortality $[10,29,30]$, and this may be partially explained by lack of financial resources to keep indoor environments cool or poorer baseline health. On the contrary, the inverse association of poverty observed for the ozone and mortality association is not consistent with prior investigations that provide evidence for an enhanced impact of ozone among populations with higher unemployment [20,31]. Whether our findings are indicative of greater/lesser susceptibility among impoverished populations or they serve as a marker for other unobserved characteristics associated with urban populations, similar to population density, cannot be distinguished from this data. In our data, a greater proportion of residents over age 65 in a county was associated with increased risk of mortality from ozone, and this is consistent with several studies that have showed that the elderly are more susceptible to the health impacts of ozone and that age is one of the strongest risk factors for ozone sensitivity [31,32]. Neither mean concentration of ozone nor mean temperature served to explain variation in the observed effect estimates.

Our analysis did have a number of limitations. We used one estimate of ozone and temperature for each county, which could have contributed to error in our exposure estimate. Our analysis was also restricted to natural causes of death, potentially underestimating the effect of temperature, as heat stroke is classified as an external cause of death. Due to data availability during the study period at the county level, we were unable to account for other environmental pollutants (e.g., particulate matter) that may also be correlated with ozone and associated with daily mortality. While some studies in the region have shown confounding of the ozone mortality association by other pollutants [33,34], other national studies have shown that the ozone mortality association is robust $[1,2]$. In our data for one county (New Haven, CT), we found no significant difference in our model results for the effect of ozone after adjusting for $\mathrm{PM}_{10}$. Our investigation of effect modification was based on county-level data and not individual-level data. Additionally, our examination of county characteristics was based on publicly

Table 4 Modification by county characteristics

\begin{tabular}{|c|c|c|c|c|c|c|c|c|}
\hline & \multicolumn{2}{|c|}{$\begin{array}{l}\text { \% Increase in mortality } \\
\text { per } 10 \text { ppb ozone, } \\
\text { adjusted for community } \\
\text { characteristic }\end{array}$} & \multicolumn{2}{|c|}{$\begin{array}{c}\text { \% Change in ozone effect } \\
\text { estimate per IQR }{ }^{1} \\
\text { increase in community } \\
\text { level variable }\end{array}$} & \multicolumn{2}{|c|}{$\begin{array}{c}\% \text { Increase in mortality } \\
90 \mathrm{~F} \text { vs } 70 \mathrm{~F} \text {, adjusted } \\
\text { for community } \\
\text { characteristic }\end{array}$} & \multicolumn{2}{|c|}{$\begin{array}{c}\text { \% Change in temperature } \\
\text { effect estimate per IQR } \\
\text { increase in community } \\
\text { level variable }\end{array}$} \\
\hline & $\begin{array}{c}\text { Central } \\
\text { estimate }\end{array}$ & $95 \% \mathrm{PI}$ & $\begin{array}{l}\text { Central } \\
\text { estimate }\end{array}$ & $95 \% \mathrm{PI}$ & $\begin{array}{c}\text { Central } \\
\text { estimate }\end{array}$ & $95 \% \mathrm{PI}$ & $\begin{array}{l}\text { Central } \\
\text { estimate }\end{array}$ & $95 \% \mathrm{PI}$ \\
\hline $\begin{array}{l}\text { No modification by } \\
\text { county characteristic }\end{array}$ & 0.55 & $(0.25,0.86)$ & - & - & 8.44 & $(7.24,9.65)$ & - & - \\
\hline \% Families Poverty & 0.64 & $(0.37,0.90)$ & -0.02 & $(-0.04,-0.01)$ & 8.21 & $(7.17,9.26)$ & 1.22 & $(0.59,1.85)$ \\
\hline Population Density & 0.66 & $(0.36,0.96)$ & -0.002 & $(-0.003,-0.0001)$ & 8.09 & $(6.94,9.26)$ & 0.08 & $(0.01,0.15)$ \\
\hline$\%$ Over 65 & 0.59 & $(0.31,0.88)$ & 4.41 & $(0.75,8.21)$ & 8.37 & $(7.20,9.55)$ & -51.42 & $(-88.29,101.45)$ \\
\hline Mean ozone & 0.56 & $(0.25,0.86)$ & 0.001 & $(-0.02,0.02)$ & 8.60 & $(7.45,9.76)$ & -0.71 & $(-1.51,0.09)$ \\
\hline Mean temperature & 0.70 & $(0.35,1.05)$ & -0.04 & $(-0.10,0.01)$ & 9.02 & $(7.66,10.40)$ & -1.81 & $(-3.78,0.21)$ \\
\hline
\end{tabular}

${ }^{1} \mathrm{IQR}=$ Interquartile Range; IQR for families in poverty $=3.6 \%$, IQR for population density $=891$ persons/mile ${ }^{2}$, IQR for residents over age $65=2.9 \%$, IQR for ozone concentration $=2.3 \mathrm{ppb}$, IQR for temperature $=3.6^{\circ} \mathrm{F}$.

All ozone results include adjustment for temperature; temperature results do not include adjustment for ozone. Estimates are based on 4 degrees of freedom/year for temporal trend. 
available data and, therefore, not exhaustive. Other factors, including baseline health, activity patterns, and other population characteristics, may also account for the variation between county effect estimates that was observed. Our novel finding of a greater magnitude of association between ozone and mortality in non-urban counties than in urban counties requires replication. However, if further work can substantiate these findings it may indicate that the public health burden of ozone has been underestimated and current regulatory standards are not fully protective.

\section{Conclusions}

We found effects of both ozone and temperature on mortality in this county-level analysis of three states in the Northeastern United States. By making use of a simple method of interpolation, we were able to estimate these associations over a wider geographic area and population than previous investigated. We also found that these associations existed in both urban and non-urban counties, with a potentially greater association between ozone and mortality in non-urban areas than in urban areas. These results indicate that the health risks brought on by climate change are not limited to urban areas and warrant further investigation.

\section{Additional file}

Additional file 1: Figure S1. Example of kriging of 8-hour maximum ozone concentrations for July 18, 1999 within the northeastern US domain Figure S2. Example of kriging of daily maximum temperature for July 18 , 1999 within the northeastern US domain.

\section{Abbreviations}

AQS: Air quality system; EPA: Environmental protection agency; ppb: Parts per billion; PI: Posterior interval.

\section{Competing interests}

The authors declare that they have no competing interests.

\section{Authors' contributions}

$J M$ contributed to the design of the study, performed the data analysis, and drafted the manuscript. DJ, GBA, and MLB contributed to the design of the study and data analysis, and helped draft the manuscript. PLK conceived and designed the study, contributed to the analysis, and helped draft the manuscript. All authors read and approved the final manuscript.

\section{Acknowledgements}

This work was funded by NOAA grant \#NA04OAR4310185. Additional funding was provided by NIEHS Center Grant \#P30 ES09089, NIEHS R01ES019560, NIEHS R21ES020152, NIEHS K99ES022631, NIEHS R21ES022585, R21ES021427, the U.S. EPA (RD 83479801) and from the Earth Institute Postdoctoral Fellows Program at Columbia University.

\section{Author details}

'Department of Environmental and Occupational Health, School of Public Health, Rutgers, The State University of New Jersey, Piscataway, NJ, USA. ${ }^{2}$ Department of Environmental Health Sciences, Mailman School of Public Health, Columbia University, New York, NY, USA. ${ }^{3}$ Department of Environmental and Radiological Health Sciences, Colorado State University, Fort Collins, CO, USA. ${ }^{4}$ School of Forestry and Environmental Studies, Yale University, New Haven, CT, USA.
Received: 3 August 2014 Accepted: 17 December 2014

Published: 7 January 2015

\section{References}

1. Bell ML, McDermott A, Zeger SL, Samet JM, Dominici F. Ozone and short-term mortality in 95 US urban communities, 1987-2000. JAMA. 2004;292:2372-8.

2. Ito K, De Leon SF, Lippmann M. Associations between ozone and daily mortality: analysis and meta-analysis. Epidemiology. 2005;16:446-57.

3. Bell ML, Dominici F, Samet JM. A meta-analysis of time-series studies of ozone and mortality with comparison to the national morbidity, mortality, and air pollution study. Epidemiology. 2005;16:436-45.

4. Gasparrini A, Armstrong B, Kovats S, Wilkinson P. The effect of high temperatures on cause-specific mortality in England and Wales. Occup Environ Med. 2012;69:56-61

5. Zanobetti A, Schwartz J. Temperature and mortality in nine US cities. Epidemiology. 2008;19:563-70.

6. Kaiser R, Le Tertre A, Schwartz J, Gotway CA, Daley WR, Rubin CH. The effect of the 1995 heat wave in Chicago on all-cause and cause-specific mortality. Am J Public Health. 2007;97 Suppl 1:S158-62.

7. Pattenden S, Armstrong B, Milojevic A, Heal MR, Chalabi Z, Doherty R, et al. Ozone, heat and mortality: acute effects in 15 British conurbations. Occup Environ Med. 2010;67:699-707.

8. Reid CE, Snowden JM, Kontgis C, Tager IB. The role of ambient ozone in epidemiologic studies of heat-related mortality. Environ Health Perspect. 2012;120:1627-30.

9. Zanobetti A, Schwartz J. Mortality displacement in the association of ozone with mortality: an analysis of 48 cities in the United States. Am J Respir Crit Care Med. 2008;177:184-9.

10. Stafoggia M, Forastiere F, Agostini D, Biggeri A, Bisanti L, Cadum E, et al. Vulnerability to heat-related mortality: a multicity, population-based, case-crossover analysis. Epidemiology. 2006;17:315-23.

11. Filleul L, Cassadou S, Médina S, Fabres P, Lefranc A, Eilstein D, et al. The relation between temperature, ozone, and mortality in nine French cities during the heat wave of 2003. Environ Health Perspect. 2006;114:1344-7.

12. Atkinson RW, Yu D, Armstrong BG, Pattenden S, Wilkinson P, Doherty RM, et al. Concentration-response function for ozone and daily mortality: results from five urban and five rural u.k. Populations. Environ Health Perspect. 2012;120:1411-7.

13. Gabriel KMA, Endlicher WR. Urban and rural mortality rates during heat waves in Berlin and Brandenburg, Germany. Environ Pollut. 2011;159:2044-50.

14. Sheridan SC, Dolney TJ. Heat, mortality, and level of urbanization: measuring vulnerability across Ohio, USA. Clim Res. 2003;24:255-65.

15. Sheridan SC, Kalkstein LS. Progress in heat watch-warning system technology. Bulletin of the American Meteorological Society. 2004;85:1931-41.

16. Bell EJ. Climate change and health research: has it served rural communities? Rural Remote Health. 2013;13:2343.

17. Zeng W, Lao X, Rutherford $S, X u Y, X u X$, Lin $H$, et al. The effect of heat waves on mortality and effect modifiers in four communities of Guangdong Province, China. Sci Total Environ. 2014;482-483:214-21.

18. Henderson SB, Wan V, Kosatsky T. Differences in heat-related mortality across four ecological regions with diverse urban, rural, and remote populations in British Columbia, Canada. Health Place. 2013;23:48-53.

19. Lippmann SJ, Fuhrmann CM, Waller AE, Richardson DB. Ambient temperature and emergency department visits for heat-related illness in North Carolina, 2007-2008. Environ Res. 2013;124:35-42.

20. Bell ML, Dominici F. Effect modification by community characteristics on the short-term effects of ozone exposure and mortality in 98 US communities. Am J Epidemiol. 2008;167:986-97.

21. Madrigano J, Mittleman MA, Baccarelli A, Goldberg R, Melly S, Klot von S, et al. Temperature, myocardial infarction, and mortality: effect modification by individual- and area-level characteristics. Epidemiology. 2013;24:439-46.

22. Anderson GB, Bell ML. Heat waves in the United States: mortality risk during heat waves and effect modification by heat wave characteristics in 43 U.S. communities. Environ Health Perspect. 2011;119:210-8.

23. Everson PJ, Morris CN. Inference for multivariate normal hierarchical models. J Royal Statistical Soc B. 2000;62:399-412.

24. Anderson BG, Bell ML. Weather-related mortality: how heat, cold, and heat waves affect mortality in the United States. Epidemiology. 2009;20:205-13.

25. Levy JI, Chemerynski SM, Sarnat JA. Ozone exposure and mortality: an empiric bayes metaregression analysis. Epidemiology. 2005;16:458-68. 
26. Martiello MA, Giacchi MV. High temperatures and health outcomes: a review of the literature. Scand J Public Health. 2010;38:826-37.

27. O'Neill MS, Jackman DK, Wyman M, Manarolla X, Gronlund CJ, Brown DG, et al. US local action on heat and health: are we prepared for climate change? Int J Public Health. 2010;55:105-12.

28. Carr JL, Sheffield PE, Kinney PL. Preparedness for climate change among local health department officials in New York state: a comparison with national survey results. J Public Health Manag Pract. 2012;18:E24-32.

29. Curriero FC, Heiner KS, Samet JM, Zeger SL, Strug L, Patz JA. Temperature and mortality in 11 cities of the eastern United States. Am J Epidemiol. 2002;155:80-7.

30. O'Neill MS, Jerrett M, Kawachi I, Levy Jl, Cohen AJ, Gouveia N, et al. Health, wealth, and air pollution: advancing theory and methods. Environ Health Perspect. 2003;111:1861.

31. Bell ML, Zanobetti A, Dominici F. Who is more affected by ozone pollution? A systematic review and meta-analysis. Am J Epidemiol. 2014;180:15-28.

32. Medina-Ramón M, Schwartz J. Who is more vulnerable to die from ozone air pollution? Epidemiology. 2008;19:672-9.

33. Ito K, Thurston GD, Silverman RA. Characterization of PM2.5, gaseous pollutants, and meteorological interactions in the context of time-series health effects models. J Expo Sci Environ Epidemiol. 2007;17 Suppl 2:545-60.

34. Gleason JA, Bielory L, Fagliano JA. Associations between ozone, PM2.5, and four pollen types on emergency department pediatric asthma events during the warm season in New Jersey: a case-crossover study. Environ Res. 2014;132:421-9

doi:10.1186/1476-069X-14-3

Cite this article as: Madrigano et al:: Temperature, ozone, and mortality in urban and non-urban counties in the northeastern United States. Environmental Health 2015 14:3.

\section{Submit your next manuscript to BioMed Central and take full advantage of:}

- Convenient online submission

- Thorough peer review

- No space constraints or color figure charges

- Immediate publication on acceptance

- Inclusion in PubMed, CAS, Scopus and Google Scholar

- Research which is freely available for redistribution 